\title{
Risk of asthma exacerbation associated with opioid and nonopioid analgesic use in children with current asthma
}

Abhishek A Nair, MS, PhD; Harold J Farber, MD, MSPH; and Hua Chen, MD, PhD

\section{What is already known about this subject}

- Package inserts of opioids contraindicate their use in patients with acute or severe bronchial asthma.

- However, risk of asthma exacerbation associated with opioid analgesics is yet to be assessed.

\section{What this study adds}

- Our study provided population-based evidence that asthma exacerbation associated with opioid analgesic use is an uncommon event.

- Risk is comparable among children receiving opioid vs nonopioid analgesics.

\author{
Author affiliations \\ AUTHOR CORRESPONDENCE: \\ Hua Chen, 832.842.8355; \\ hchen25@central.uh.edu
}

Abhishek A Nair, MS, PhD, and Hua Chen, MD, PhD, Department of Pharmaceutical Health Outcomes and Policy, College of Pharmacy, University of Houston, Houston TX. Harold J Farber, MD, MSPH, Department of Pediatrics, Section of Pulmonology, Baylor College of Medicine and Texas Children's Hospital, Houston, TX, and Medical Affairs, Texas Children's Health Plan, Houston, TX.

J Manag Care Spec Pharm. 2022;28(3):325-35

Copyright $(2022$, Academy of Managed Care Pharmacy. All rights reserved.

\section{ABSTRACT}

BACKGROUND: In the United States, asthma occurs in a vast proportion of children and adolescents. Asthma exacerbation is an acute episodic event typically characterized by difficulty in breathing, chest tightness, coughing, or wheezing. Severe asthma exacerbation can be life-threatening and lead to service utilizations such as hospitalizations and emergency department (ED) visits. Opioid analgesic use can trigger an asthma exacerbation through 2 pharmacological mechanisms. Despite the potential mechanisms, there is lack of empirical evidence to determine the risk of asthma exacerbation and its association with opioid use.
OBJECTIVE: To evaluate the risk of asthma exacerbation in children with current asthma receiving an opioid vs a nonopioid analgesic.

METHODS: Eligible individuals aged under 18 years with current asthma and receiving an incident analgesic prescription were identified from a large Medicaid managed care database during 2013-2018. Current asthma was defined as receipt of an asthma diagnosis and an antiasthmatic medication in the 12 months before analgesic medication initiation. Asthma exacerbation was defined as a hospitalization or ED visit with asthma as either the primary or secondary diagnosis within 3 days of receipt of an analgesic prescription. A weighted multivariable logistic regression using inverse probability treatment weighting was performed to test the association between use of analgesic medication and risk of asthma exacerbation.

RESULTS: This study included 13,359 children with current asthma who filled either an incident opioid ( $n=5,363,40.1 \%$ ) or nonopioid analgesic $(n=7,996,59.9 \%)$ prescription. Asthma exacerbation was observed in $24(0.5 \%)$ opioid analgesic recipients and $22(0.3 \%)$ nonopioid analgesic recipients within 3 days of analgesic initiation. Weighted logistic regression results showed that children receiving opioid analgesics (adjusted odds ratio $=1.6,95 \% \mathrm{Cl}=0.9-2.9$ ) did not have a statistically significantly higher risk of asthma exacerbation than their nonopioid analgesic recipient counterparts in the propensity score-weighted multivariable analysis. 
CONCLUSIONS: Asthma exacerbation associated with analgesic use in children with current asthma was an uncommon event, and the risk was comparable among children receiving opioid vs nonopioid analgesics.

As estimated by the 2016 National Health Interview Survey, parent reports of doctor-diagnosed asthma indicated that asthma was present in $7.5 \%$ of noninstitutionalized children aged under 18 years in the United States. ${ }^{1}$ Of those with an asthma diagnosis and receiving antiasthmatic treatment during 2016, 53.8\% experienced an asthma exacerbation in the 12 months before the survey. ${ }^{2}$ Asthma exacerbations are acute episodic events typically characterized by difficulty in breathing (dyspnea), chest tightness, coughing, or wheezing. Severe asthma exacerbations can be potentially life-threatening and may warrant an emergency department (ED) visit or hospitalization. ${ }^{3,4}$

Opioid and nonopioid analgesics are frequently dispensed to children for the management of acute pain. For patients undergoing an outpatient surgical procedure, a dental procedure, or experiencing a traumatic injury, opioid analgesics have been the mainstay pain management modality in the outpatient setting. ${ }^{5-7}$ For other pain diagnoses such as back pain, musculoskeletal pain, and abdominal pain, nonopioid analgesics are the main pharmacologic therapy.

Package inserts for hydrocodone, codeine, and tramadol include a contraindication warning for patients "with acute or severe bronchial asthma in an unmonitored setting or in the absence of resuscitative equipment." ${ }^{8-11}$ Opioids could potentially trigger asthma exacerbation through 2 pharmacological mechanisms. One mechanism is microglial activation via toll-like receptors 4 (TLR4), releasing proinflammatory mediators such as cytokines, interleukins, prostaglandins, and histamine from mast-cells, ${ }^{4,12-14}$ which can precipitate a pseudo-allergic reaction causing airway hyper-responsiveness, flushing, and hives thus exacerbating asthma. The second mechanism is the depression of respiration by opioids through their activity on the respiratory center at the base of the brain, causing a fall in the respiratory drive, respiratory rate, and tidal volume, ${ }^{12,14-16}$ which could result in respiratory failure in the event of a severe asthma exacerbation.

Despite the potential mechanisms and the US Food and Drug Administration (FDA) warnings, the risk of asthma exacerbation associated with opioid analgesics has yet to be assessed by empirical or epidemiological studies. To bridge the knowledge gap, our study aimed to quantify the risk of asthma exacerbation associated with the use of opioid analgesics vs alternative pharmacotherapies (nonopioid analgesics) by children with current asthma.

\section{Methods}

\section{DATA}

Our study used the deidentified claims data between January 1, 2013, and December 31, 2018, from the Texas Children's Health Plan (TCHP). Founded in 1996 by the Texas Children's Hospital, TCHP is the nation's first managed care organization created for children. TCHP offers managed Medicaid and Children's Health Insurance Program (CHIP) for children in eastern and southeastern Texas. The data used in this study included patient demographics (age, sex, race, and Medicaid eligibility dates); medical claims (outpatient service utilizations and indicators for hospitalization and ED visits); and pharmacy claims (outpatient prescription use with dosages and prescriber specialties). Moreover, since Texas Medicaid covers over-the-counter nonopioid pain relievers such as acetaminophen, ibuprofen, naproxen, and aspirin, head-to-head comparison between opioid analgesics and alternative nonopioid analgesics is possible.

\section{STUDY DESIGN}

A retrospective cohort design was applied to assess the risk of asthma exacerbation associated with analgesic exposures. Compared with other common epidemiological designs, the cohort design provided a more clear temporal causation, since the exposure was identified before the outcome and "provid[ed] the strongest scientific evidence."17,18

Inclusion Criteria. Individuals enrolled in TCHP between January 1, 2013, and December 31, 2018, were included if they had current asthma, received an incident prescription for opioid or nonopioid analgesics, and were aged 1-17 years on the date that the incident analgesic prescription was filled. This time frame was selected mainly because 2012 was the year that the opioid epidemic was at its peak, and between 2013 and 2018, the FDA issued an array of warnings and contraindications to reduce opioid analgesic use in children "experiencing acute or bronchial asthma." ${ }^{19,20}$

Current asthma was defined as the presence of asthma as the primary or secondary reason for a physician visit, along with receipt of an antiasthmatic medication in the 1-year period before the index analgesic prescription. The International Classification of Diseases, Ninth Revision, Clinical Modification (ICD-9-CM) and International Classification of Diseases, Tenth Revision, Clinical Modification, (ICD-10-CM) medical diagnoses codes were used to identify asthma diagnoses (ICD-9-CM: 


\section{TABLE 1}

Covariate Balance Assessment Before and After IPTW Propensity Score Adjustment for Opioid and Nonopioid Recipients

\begin{tabular}{|c|c|c|c|c|c|c|}
\hline \multirow[b]{2}{*}{ Characteristics } & \multicolumn{3}{|c|}{ Before IPTW } & \multicolumn{3}{|c|}{ After IPTW } \\
\hline & $\begin{array}{c}\text { Opioid } \\
n=5,363 \\
n(\%)\end{array}$ & $\begin{array}{c}\text { Nonopioid } \\
n=7,996 \\
n(\%)\end{array}$ & $\begin{array}{c}\text { Standardized } \\
\text { mean } \\
\text { difference }\end{array}$ & $\begin{array}{c}\text { Opioid } \\
n=5,363 \\
n(\%)\end{array}$ & $\begin{array}{c}\text { Nonopioid } \\
n=7,996 \\
n(\%)\end{array}$ & $\begin{array}{c}\text { Standardized } \\
\text { mean } \\
\text { difference }\end{array}$ \\
\hline Age, mean \pm SD & $10.2 \pm 4.9$ & $7.4 \pm 4.4$ & $0.61^{a}$ & $8.6 \pm 5.1$ & $8.5 \pm 4.7$ & $0.06^{a, b}$ \\
\hline \multicolumn{7}{|l|}{ Sex } \\
\hline Female vs male & $2,451 \quad(45.7)$ & $3,686 \quad(46.1)$ & -0.01 & $2,624 \quad(47.1)$ & $3,633 \quad(45.4)$ & $0.02^{\mathrm{b}}$ \\
\hline \multicolumn{7}{|l|}{ Race } \\
\hline Alaskan American & $20 \quad(0.4)$ & $(0.2)$ & -0.02 & $(0.2)$ & $(0.3)$ & $0.02^{b}$ \\
\hline Asian & $90 \quad(1.7)$ & $145 \quad(1.8)$ & 0.01 & $114 \quad(2.1)$ & $136 \quad(1.7)$ & $-0.03^{b}$ \\
\hline Hispanic & $2,877 \quad(53.7)$ & $4,973 \quad(62.2)$ & 0.17 & $2,664 \quad(47.8)$ & $4,553 \quad(56.9)$ & $0.08^{b}$ \\
\hline Non-Hispanic Black & $977 \quad(18.2)$ & $1,264 \quad(15.8)$ & -0.06 & $1,178 \quad(21.1)$ & $1,415 \quad(17.7)$ & $-0.06^{\star}$ \\
\hline Non-Hispanic White & $910 \quad(17.0)$ & $634 \quad(7.9)$ & $-0.28^{a}$ & $760 \quad(13.6)$ & $1,011 \quad(12.6)$ & $-0.02^{a, b}$ \\
\hline Unknown & $489 \quad(9.1)$ & $961 \quad(12.0)$ & 0.09 & $847 \quad(15.2)$ & $857 \quad(10.7)$ & $0.00^{\mathrm{b}}$ \\
\hline \multicolumn{7}{|l|}{ Medicaid eligibility } \\
\hline Medicaid vs CHIP & $4,765 \quad(88.9)$ & $7,122 \quad(89.1)$ & 0.01 & $4,965 \quad(89.1)$ & $7,104 \quad(88.8)$ & $0.01^{a}$ \\
\hline \multicolumn{7}{|l|}{ Provider specialty } \\
\hline Dentists & $1,305 \quad(24.3)$ & $(7.8)$ & $-0.46^{a}$ & $769 \quad(13.8)$ & $1,149 \quad(14.4)$ & $-0.02^{a, b}$ \\
\hline ED prescribers & $912 \quad(17.0)$ & $(8.0)$ & $-0.27^{a}$ & $608 \quad(10.9)$ & $1,002 \quad(12.5)$ & $0.04^{a, b}$ \\
\hline $\begin{array}{l}\text { Obstetrics and gynecology } \\
\text { specialists }\end{array}$ & $65 \quad(1.2)$ & $(0.4)$ & -0.09 & $(0.6)$ & $(0.7)$ & $-0.02^{b}$ \\
\hline Other specialists & $132 \quad(2.5)$ & $118 \quad(1.5)$ & -0.07 & $117 \quad(2.1)$ & $(2.1)$ & $-0.06^{\mathrm{b}}$ \\
\hline Physician assistants & $96 \quad(1.8)$ & $314 \quad(3.9)$ & 0.13 & $155 \quad(2.8)$ & (3.1) & $-0.01^{b}$ \\
\hline Primary care providers & $658 \quad(12.3)$ & $5,660 \quad(70.8)$ & $1.48^{\mathrm{a}}$ & $2,778 \quad(49.8)$ & $3,778 \quad(47.2)$ & $0.00^{\mathrm{a}, \mathrm{b}}$ \\
\hline Surgical specialists (surgeons) & $2,195 \quad(40.9)$ & $611 \quad(7.6)$ & $-0.84^{a}$ & $1,113 \quad(20.0)$ & $1,594 \quad(20.0)$ & $-0.01^{a, b}$ \\
\hline
\end{tabular}

continued on next page

493; ICD-10-CM: J45, J46). ${ }^{3,21-25}$ Anticholinergics, combination inhaled medicines, inhaled corticosteroids, inhaled long-acting beta agonists, leukotriene modifiers, mast cell inhibitors, methylxanthines, oral corticosteroids, and short-acting beta agonists were the antiasthmatic medications included in the study (Supplementary Table 1, available in online article).

An incident analgesic use was defined as the receipt of an opioid or nonopioid analgesic with no previous use of these medications for 1 year. Generic Product Identifier (GPI) codes were used to identify prescription opioid analgesics (eg, codeine, hydrocodone, and tramadol); nonopioid analgesics (eg, nonsteroidal anti-inflammatory drugs [NSAIDs]); and other analgesics (eg, acetaminophen; Supplementary Tables 2 and 3 , available in online article).
Exclusion Criteria. Individuals who did not have continuous enrollment in the 1-year period before (baseline) and 7-day period (maximum follow-up for sensitivity analysis) after the index analgesic prescription were excluded from the study sample. Children and adolescents with a diagnosis of malignancy or sickle-cell disease during the study period were excluded from the cohort because these are chronic pain conditions for which opioid analgesics are given continually and for a longer duration. Additionally, all analgesic users with only a respiratory infection diagnosis presented within 30 days before the index analgesic prescription were excluded, since respiratory infections are a common trigger of asthma exacerbations.

It is stated in the package inserts of opioid analgesics that the risk of respiratory side effects is significantly higher in the initial 24-72 hours of the drug administration..$^{5-8}$ 


\section{TABLE 1 Covariate Balance Assessment Before and After IPTW Propensity Score Adjustment for Opioid and Nonopioid Recipients (continued)}

\begin{tabular}{|c|c|c|c|c|c|c|}
\hline \multirow[b]{2}{*}{ Characteristics } & \multicolumn{3}{|c|}{ Before IPTW } & \multicolumn{3}{|c|}{ After IPTW } \\
\hline & $\begin{array}{l}\text { Opioid } \\
n=5,363 \\
n(\%)\end{array}$ & $\begin{array}{c}\text { Nonopioid } \\
n=7,996 \\
n(\%)\end{array}$ & $\begin{array}{c}\text { Standardized } \\
\text { mean } \\
\text { difference }\end{array}$ & $\begin{array}{c}\text { Opioid } \\
n=5,363 \\
n(\%)\end{array}$ & $\begin{array}{l}\text { Nonopioid } \\
n=7,996 \\
n(\%)\end{array}$ & $\begin{array}{c}\text { Standardized } \\
\text { mean } \\
\text { difference }\end{array}$ \\
\hline \multicolumn{7}{|l|}{ Procedures and diagnoses } \\
\hline Abdominal pain & $(2.7)$ & $1,389 \quad(17.4)$ & $0.50^{\mathrm{a}}$ & $452 \quad(8.1)$ & $907 \quad(11.3)$ & $0.02^{a, b}$ \\
\hline Back pain & $62 \quad(1.2)$ & $164 \quad(2.1)$ & 0.07 & $96 \quad(1.7)$ & $133 \quad(1.7)$ & $-0.02^{\mathrm{b}}$ \\
\hline Dental surgery/procedure & $1,305 \quad(24.3)$ & $623 \quad(7.8)$ & $-0.46^{\mathrm{a}}$ & $769 \quad(13.8)$ & $1,149 \quad(14.4)$ & $-0.02^{a, b}$ \\
\hline General infection & $125 \quad(2.3)$ & $1,621 \quad(20.3)$ & $0.59^{a}$ & 662 (11.9) & $1,036 \quad(13.0)$ & $0.03^{a, b}$ \\
\hline Generalized pain & $63 \quad(1.2)$ & $385 \quad(4.8)$ & 0.21 & $335 \quad(6.0)$ & $271 \quad(3.4)$ & $0.02^{\mathrm{b}}$ \\
\hline Headache and migraine & $73 \quad(1.4)$ & $548 \quad(6.9)$ & $0.28^{\mathrm{a}}$ & $502 \quad(9.0)$ & $372 \quad(4.7)$ & $0.01^{a, b}$ \\
\hline Musculoskeletal pain & $125 \quad(2.3)$ & $556 \quad(7.0)$ & 0.22 & $241 \quad(4.3)$ & $401 \quad(5.0)$ & $-0.03^{b}$ \\
\hline Outpatient surgery/procedure & $2,104 \quad(39.2)$ & $908 \quad(11.4)$ & $-0.67^{a}$ & $1,179 \quad(21.2)$ & $1,771 \quad(22.2)$ & $0.00^{a, b}$ \\
\hline Trauma & $1,336 \quad(24.9)$ & $1,716 \quad(21.5)$ & -0.08 & $1,308 \quad(23.5)$ & $1,892 \quad(23.7)$ & $-0.02^{\mathrm{b}}$ \\
\hline \multicolumn{7}{|l|}{ Asthma risk factors } \\
\hline $\begin{array}{l}\text { History of asthma-related ED } \\
\text { visit }\end{array}$ & $598 \quad(11.2)$ & $499 \quad(6.2)$ & -0.17 & $472 \quad(8.5)$ & $(9.1)$ & $-0.03^{b}$ \\
\hline $\begin{array}{l}\text { History of asthma-related } \\
\text { hospitalization }\end{array}$ & $103 \quad(1.9)$ & $65 \quad(0.8)$ & -0.1 & $73 \quad(1.3)$ & $104 \quad(1.3)$ & $-0.01^{b}$ \\
\hline SABA overuse & $247 \quad(4.6)$ & $219 \quad(2.7)$ & -0.09 & $202 \quad(3.6)$ & $295 \quad(3.7)$ & $-0.03^{b}$ \\
\hline $\begin{array}{l}\text { Providers prescribing analgesic } \\
\text { and antiasthmatic medications } \\
\text { to the same patient }\end{array}$ & $156 \quad(2.9)$ & $2,777 \quad(34.7)$ & $0.89^{a}$ & $1,597 \quad(28.7)$ & $1,756 \quad(22.0)$ & $-0.08^{a, b}$ \\
\hline
\end{tabular}

Therefore, the main analyses focused on asthma exacerbation within 3 calendar days following the index analgesic prescription. Sensitivity analyses were conducted to determine the risk of asthma exacerbation within 4 days and 7 days after the index analgesic prescription. The 4-day and 7-day time frames for the sensitivity analysis were selected because analgesic prescriptions may not be taken exactly as instructed, and the risk of asthma exacerbation may not be completely eliminated after the first 3 days of treatment, even though the risk is highest in the first 24-72 hours.

\section{OUTCOME MEASURE: ASTHMA EXACERBATION}

A joint European Respiratory/American Thoracic Society (ERATS) statement proposed a definition of "asthma exacerbation" for retrospective study-based research as "any of the following service utilizations with an asthma diagnosis in the primary or secondary position: hospitalization, emergency department (ED) visit, or physician office or outpatient visit with a pharmacy claim for oral corticosteroids (OCS)." ${ }^{26-30}$

Because asthma-associated hospitalization and ED visits are considered the more definite criteria than an OCS utilization pattern for identifying asthma exacerbation, we used an operational definition stricter than the ERATS statement in the main analysis and defined asthma exacerbation associated with an analgesic prescription as a hospitalization or ED visit with asthma as the primary or secondary diagnosis within 3 days after the incident analgesic prescription. For the sensitivity analysis, we tested the robustness of the main findings using a more lenient definition that included not only an asthma-associated ED visit and hospitalization, but also the dispensing of an OCS within 3 days after the incident analgesic prescription. 


\section{FIGURE 1 Cohort Development for Current Asthma Patients Receiving Analgesic} (Opioid/Nonopioid) Medications and Experiencing Asthma Exacerbations

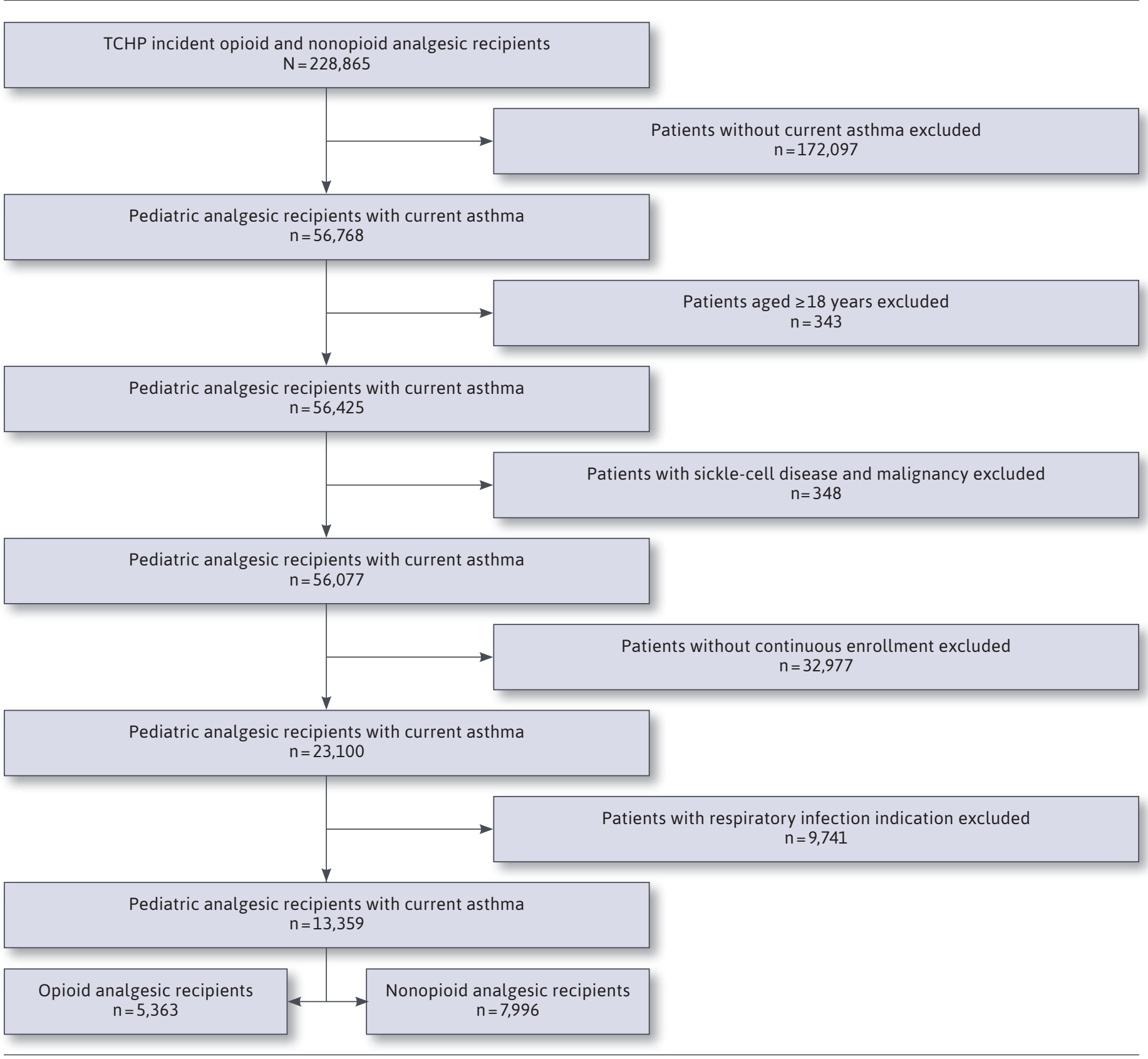

TCHP = Texas Children's Health Plan.

\section{COVARIATES}

Patient and provider characteristics (Table 1) that could confound the association between the index analgesic prescription and the risk of asthma exacerbation were identified during the 1-year period before the index prescriptions according to the Andersen Behavioral Model. . $^{31,32}$ Predisposing factors such as age, sex, self-reported race/ ethnicity, and health plan eligibility category (Medicaid 


\begin{tabular}{|c|c|c|c|c|}
\hline $\begin{array}{c}\text { Patients experiencing asthma exacerbation } \\
\text { during follow-up period }\end{array}$ & $\begin{array}{l}\text { Opioid analgesic } \\
\text { recipients } \\
n=5,363(100 \%)\end{array}$ & $\begin{array}{l}\text { Nonopioid analgesic } \\
\text { recipients } \\
\mathbf{n}=7,996(100 \%)\end{array}$ & $\begin{array}{l}\text { Chi-square test } \\
\text { statistic }\end{array}$ & $P$ value \\
\hline \multicolumn{5}{|l|}{ Main findings ${ }^{a}$} \\
\hline Asthma exacerbation (3-day follow-up) & $24 \quad(0.5)$ & $22 \quad(0.3)$ & 2.78 & 0.09 \\
\hline \multicolumn{5}{|l|}{ Sensitivity findings (on duration of follow-up) ${ }^{a}$} \\
\hline Asthma exacerbation (4-day follow-up) & $(0.5)$ & $(0.4)$ & 1.60 & 0.21 \\
\hline Asthma exacerbation (7-day follow-up) & $37 \quad(0.7)$ & $41 \quad(0.5)$ & 1.74 & 0.19 \\
\hline \multicolumn{5}{|c|}{ Sensitivity findings (on operational definition and duration of follow-up) ${ }^{b}$} \\
\hline Asthma exacerbation (3-day follow-up) & $32 \quad(0.6)$ & $34 \quad(0.4)$ & 1.92 & 0.17 \\
\hline Asthma exacerbation (4-day follow-up) & $39 \quad(0.7)$ & $48 \quad(0.6)$ & 0.80 & 0.37 \\
\hline Asthma exacerbation (7-day follow-up) & $54 \quad(1.0)$ & $81 \quad(1.1)$ & 0.001 & 0.97 \\
\hline \multicolumn{5}{|c|}{$\begin{array}{l}\text { 'This definition of asthma exacerbation includes service utilizations corresponding to hospitalizations or ED visits with an asthma diagnosis. } \\
\text { 'This definition of asthma exacerbation includes service utilizations corresponding to hospitalizations, ED visits, or oral corticosteroid prescription associated with } \\
\text { an outpatient visit with an asthma diagnosis claim in the primary or secondary position. } \\
\text { ED=emergency department. }\end{array}$} \\
\hline
\end{tabular}

vs CHIP) were the factors present before the treatment. Enabling factors such as provider specialty constituted an individual's ability to secure health services. Need factors such as previous history of procedures, diagnoses, and asthma severity provided insight into the individual's health status, the likelihood of receiving opioid vs nonopioid analgesics, and the preexisting risk of having an asthma exacerbation.

Asthma severity was defined as asthma-related hospitalization, ED visit, and short-acting beta agonist (SABA) overuse during the 12 months before the index period. Asthma-related hospitalization and ED visit was defined as correspondent service utilizations with asthma as the primary or the secondary diagnosis. ${ }^{30}$ Presence of 6 or more SABA prescriptions in the baseline year qualified as overuse. $^{25,33,34}$

\section{STATISTICAL ANALYSIS}

Bivariate statistics for sociodemographic, clinical, and provider factors for patients receiving an opioid vs nonopioid analgesic were compared using chi-square tests at a statistical significance of $\alpha=0.05$ (95\% significance level).

Propensity scores (PS) for the receipt of opioid vs nonopioid analgesics were obtained using a multivariable logistic regression model with receipt of an opioid vs nonopioid as the outcome and the patient and provider factors as the potential covariates. Among different PS methods, inverse probability treatment weighting (IPTW) was applied. IPTW is the inverse of the probability of receiving the respective treatment. ${ }^{35,36}$ There are several ways to use the resulting PS (eg, matching, stratification, and modeling), but weighting by a function of the PS has several advantages. Weighting allows all patients to contribute to the analysis, whereas matching usually inherently excludes some patients. The PS-based IPTWs were estimated, using Proc psmatch in SAS, to create a pseudo-population of opioid and alternative analgesic users balanced on all the measured covariates. ${ }^{37}$ The balance of covariates between opioid and nonopioid analgesic groups was confirmed using the standardized differences with a satisfactory threshold value between -0.25 and 0.25 .

A weighted logistic regression model was fitted to estimate the adjusted odds ratio (aOR) and the corresponding 95\% CIs for the risk of asthma exacerbation associated with receipt of opioid vs nonopioid analgesics. All analyses were performed using SAS Enterprise Guide, version 8.1 (SAS Institute) statistical software. ${ }^{38}$

The University of Houston and the Baylor College of Medicine institutional review boards approved the study and granted a waived informed consent.

\section{Results}

Of the 228,865 pediatric analgesic recipients enrolled in TCHP between January 1, 2013, and December 31, 2018, $56,768(24.8 \%)$ received a diagnosis of asthma and filled an antiasthmatic prescription during the 1-year period before the index analgesic prescription. After excluding patients who were aged more than 18 years $(n=343)$, had malignancy 


\section{FIGURE 2 Covariate Balance Assessment Opioid and Nonopioid Analgesic Recipients After IPTW Adjustment}
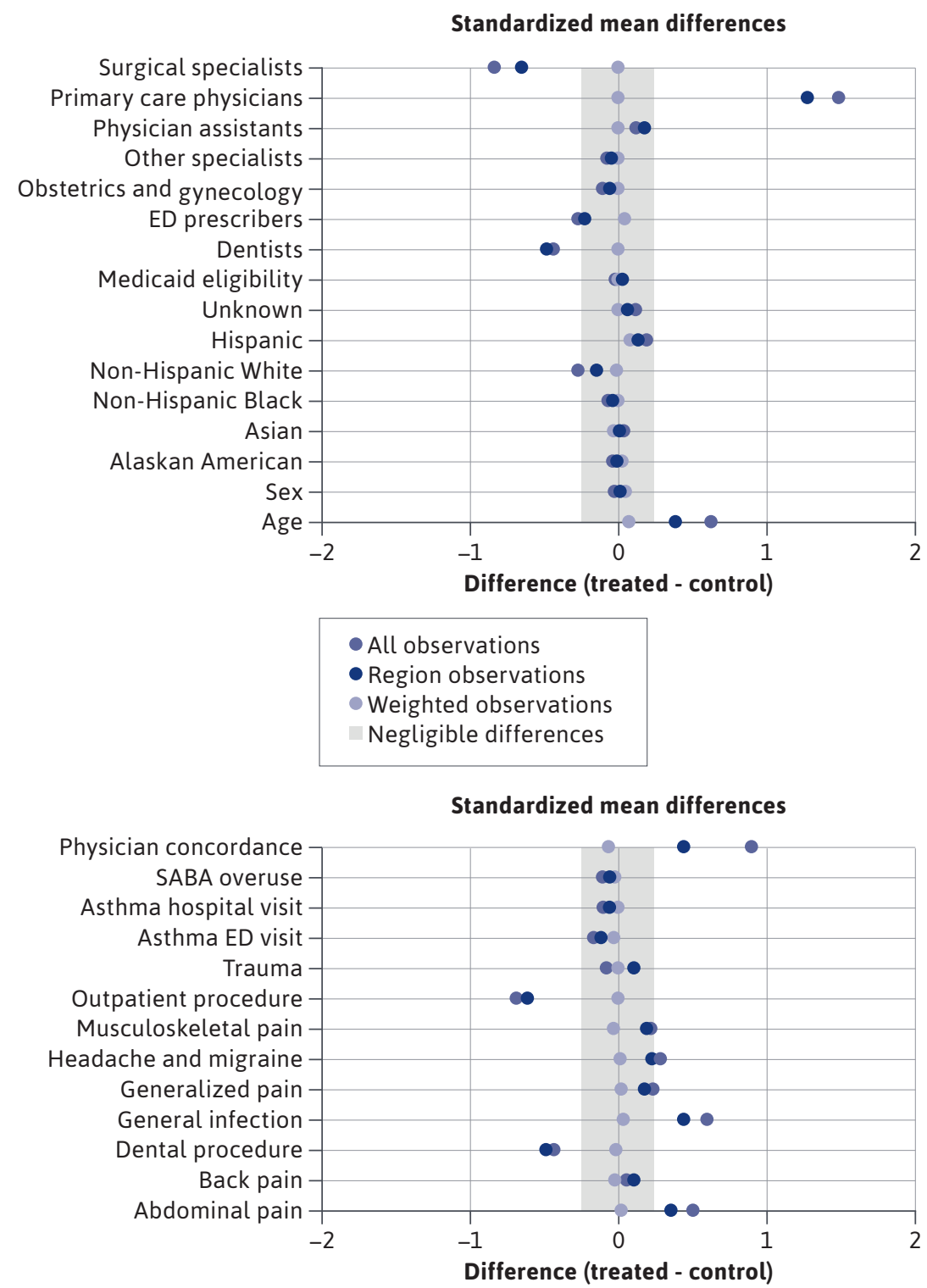

Note: This figure represents the overall covariate balance between the treated (opioid recipients) and control (nonopioid recipients) expressed as standardized mean difference after IPTW adjustment. The weighted observations (+) lie within the -0.25-0.25 limit, indicating that after IPTW propensity score adjustment the treated and control groups are similar on the basis of all baseline covariates included in the propensity score model.

$E D=$ emergency department; IPTW = inverse probability of treatment weighting; SABA = short-acting beta agonist. and sickle-cell disease $(\mathrm{n}=343)$, were without continuous eligibility $(\mathrm{n}=32,982)$, and had their primary analgesic use associated with respiratory infections $(n=9,741)$, the final cohort comprised 13,359 children and adolescents. Of these, 5,363 (40.1\%) received opioid analgesics, and 7,996 (59.9\%) received nonopioid analgesics (Figure 1). The average (SD) duration of analgesic therapy was 5.4 (4.1) days in the opioid group and 7.4 (5.9) days in the nonopioid group.

\section{DESCRIPTIVE CHARACTERISTICS OF OPIOID AND NONOPIOID RECIPIENTS WITH CURRENT ASTHMA}

Patient Demographics. The opioid analgesic recipients were older $(10.2$ [4.9] years) compared with the nonopioid analgesic recipients (7.4 [4.4] years). The proportion of non-Hispanic White children in the opioid group (17.0\%) were 2 times more than that in the nonopioid group (7.9\%). In contrast, there was a significantly lower proportion of Hispanic children (53.7\%) in the opioid group than in the nonopioid group (62.2\%; Table 1).

Provider Characteristics. The opioid analgesic prescriptions were prescribed commonly by surgical specialists $(n=2,195,40.9 \%)$, dentists $(n=1,305, \quad 24.3 \%)$ and emergency department (ED) prescribers $(n=912$, $17.0 \%$ ), whereas the nonopioid analgesics were predominantly prescribed by primary care providers $(n=5,660$, $70.8 \%)$.

Diagnoses and Procedures. The procedures and diagnoses most commonly observed in the opioid recipients were outpatient surgery $(\mathrm{n}=2,104,39.2 \%)$, traumatic injury $(\mathrm{n}=1,336,24.9 \%)$, and dental procedures $(n=1,305,24.3 \%)$. The majority of the nonopioid recipients received their analgesics for traumatic injury 
TABLE 3 Unadjusted and IPTW-Adjusted Association Between Receipt of Opioid vs Nonopioid Analgesics and Risk of Asthma Exacerbation in Children and Adolescents

\begin{tabular}{|c|c|c|c|c|}
\hline Characteristics & $\begin{array}{c}\text { Unadjusted OR } \\
(95 \% \mathrm{CI})\end{array}$ & $P$ value & $\begin{array}{c}\text { IPTW-adjusted OR } \\
(95 \% \mathrm{CI})\end{array}$ & $P$ value \\
\hline \multicolumn{5}{|l|}{ Main findings ${ }^{a}$} \\
\hline Opioid vs nonopioid recipients (3-day follow-up) & $1.6(0.9-2.9)$ & 0.09 & $1.6(0.9-2.9)$ & 0.10 \\
\hline \multicolumn{5}{|l|}{ Sensitivity findings (on duration of follow-up) ${ }^{a}$} \\
\hline Opioid vs nonopioid recipients (4-day follow-up) & $1.4(0.8-2.3)$ & 0.21 & $1.0 \quad(0.6-1.7)$ & 0.92 \\
\hline Opioid vs nonopioid recipients (7-day follow-up) & $1.3(0.9-2.1)$ & 0.19 & $1.4 \quad(0.9-2.1)$ & 0.06 \\
\hline \multicolumn{5}{|c|}{ Sensitivity findings (on operational definition and duration of follow-up) ${ }^{b}$} \\
\hline Opioid vs nonopioid recipients (3-day follow-up) & $1.4 \quad(0.9-2.3)$ & 0.17 & $1.4 \quad(0.9-2.2)$ & 0.12 \\
\hline Opioid vs nonopioid recipients (4-day follow-up) & $1.2(0.8-1.9)$ & 0.37 & $1.0 \quad(0.7-1.5)$ & 0.91 \\
\hline Opioid vs nonopioid recipients (7-day follow-up) & $1.0(0.8-1.5)$ & 0.97 & $1.1 \quad(0.8-1.5)$ & 0.51 \\
\hline
\end{tabular}

Note: Unweighted logistic regression and IPTW logistic regression models were used for the unadjusted and adjusted analyses, respectively.

aThis definition of asthma exacerbation includes service utilizations corresponding to hospitalizations or ED visits with an asthma diagnosis.

'This definition of asthma exacerbation includes service utilizations corresponding to hospitalization, ED visits or oral corticosteroid prescriptions associated with outpatient visits with asthma diagnosis claims in the primary or secondary position.

$E D=$ emergency department; IPTW = inverse probability of treatment weighting; $O R=$ odds ratio.

$(\mathrm{n}=1,716,21.5 \%)$, general infections $(\mathrm{n}=1,621,20.3 \%)$, and abdominal pain $(\mathrm{n}=1,389,17.4 \%)$.

Health Care Utilization History Associated With Uncontrolled Asthma. A relatively higher proportion of children in the opioid analgesic group had previous histories of asthma-related ED visits (opioid group: $11.2 \%$; nonopioid group: $6.2 \% ; \mathrm{P}<0.001$ ) and SABA overuse (opioid group: 4.6\%; nonopioid group: $2.7 \%$; $P<0.001$ ) compared with those in the nonopioid group.

\section{INCIDENT ASTHMA EXACERBATION FOLLOWING THE EXPOSURE TO OPIOID AND NONOPIOID ANALGESICS}

Twenty-four (0.5\%) children with incident opioid analgesic prescriptions and $22(0.3 \%)$ children with incident nonopioid analgesic prescriptions had asthma-associated hospital admissions or ED visits within 3 days following the analgesic dispensing $(P=0.09$; Table 2$)$.

\section{WEIGHTED LOGISTIC REGRESSION ANALYSIS OF THE RISK OF ASTHMA EXACERBATION ASSOCIATED WITH EXPOSURE TO OPIOID VS NONOPIOID ANALGESICS}

After the adjustment using IPTW, all the baseline covariates were comparable between opioid and nonopioid analgesic recipients. The standardized mean differences on covariates that were different before the adjustment, such as patient demographics, provider characteristics, patient diagnosis and procedures, and their health care utilization history associated with uncontrolled asthma, were not statistically significant (Table 1 and Figure 2). More details about IPTW estimation and application are described in the Supplementary Appendix (available in the online article).

The results of IPTW logistic regression (Table 3) showed that the risk of asthma exacerbation within 3 days of analgesic dispensing was comparable $(\mathrm{aOR}=1.6,95 \% \mathrm{CI}=0.9-2.9)$ between opioid and nonopioid recipients.

\section{SENSITIVITY ANALYSIS}

The risk of asthma-related ED visits and hospital admissions remained comparable between opioid and nonopioid analgesic recipients after changing the duration of follow-up to 4 days $(\mathrm{aOR}=1.0,95 \% \mathrm{CI}=0.6-1.7)$ and 7 days $(\mathrm{aOR}=1.4,95 \%$ $\mathrm{CI}=0.9-2.1$; Table 3).

Using a more lenient asthma exacerbation definition that included asthma-related ED visits, hospital admissions, and OCS overuse, the adjusted analysis showed that asthma exacerbation rates were still low, and the association between opioid exposure and asthma exacerbation remained statistically insignificant $(\mathrm{aOR}=1.4,95 \% \mathrm{CI}=0.9$ 2.2). Similarly, for extended follow-up durations of 4 days and 7 days, the risk of asthma exacerbation was comparable and not statistically significant (Table 3 ).

\section{Discussion}

Opioid use in children has long been a public health concern. Since 2012, the FDA has issued a series of labeling 
changes for the use of codeine, tramadol, and hydrocodone in children and adolescents. ${ }^{19,20}$ These warnings highlight the potential risk of opioids in precipitating respiratory depression in children with a compromised airway function, ${ }^{19,20}$ based on isolated case reports that indicated opioid use could lead to side effects such as difficulty breathing and in rare instances culminating in death. ${ }^{39}$

Similar to other FDA warnings associated with opioid use in children, the FDA contraindication for the use of codeine, hydrocodone, and tramadol in patients "with acute or severe bronchial asthma" was issued without the support of any published pediatric data. ${ }^{8-11}$ The FDA issued this contraindication warning based on what is known about the pharmacological mechanisms of action associated with opioids, rather than the real-world patient data, that may precipitate a risk of asthma exacerbation through various pathways., ${ }^{42-16}$

After the FDA contraindication warning was issued, the available evidence supporting the warning has been limited to illicit drug users and adults with opioid use disorder. There have been case reports of asthma exacerbation among adults following the use of either injectable or inhaled heroin and the use of a transdermal fentanyl patch. ${ }^{40-43}$ The risk of asthma associated with opioid use was also reported in a recent case-control study among adults with opioid use disorder. ${ }^{44}$

Our findings bridge the gap and clarify the safety concern associated with the use of prescription analgesics by children with asthma for pediatric practitioners who often need to prescribe opioid analgesics, such as surgeons, ED physicians, and dentists. The findings suggest that the asthma exacerbation event following a prescription analgesic administration among children with current asthma was uncommon $(0.3 \%-0.5 \%)$. Opioid analgesics do not cause a significantly higher risk of asthma exacerbation compared with nonopioid analgesics in children.

Medication safety in a vulnerable patient population, such as children, has always been a concern in medical society. However, in contrast to its importance, limited data are available to understand the comparative safety between perceived high-risk medications, such as opioids, and their alternatives, such as NSAIDs, which have posed significant barriers to appropriate medication use in children. Additional pediatric data are needed to help policymakers, prescribers, and patients interpret the implications of the FDA warnings for minors.

\section{LIMITATIONS}

Despite the significant implication of our study findings, this study has limitations. Our study sample included only Medicaid and CHIP-enrolled children and adolescents living in southeast Texas. The sample predominantly consisted of Hispanics (53\%). The results might not be generalizable to more affluent populations and/ or to populations with substantially different ethnicities.

In addition, a considerable number of pediatric analgesic recipients in our cohort were excluded either because of the lack of continuous Medicaid or CHIP coverage (enrollment) during the study period or because of the lack of a long enough analgesicfree period to establish an incident user status. These patients were excluded to ensure a strong internal validity in terms of identifying the outcome (asthma exacerbation) and its temporally associating with the exposure (receipt of an incident opioid vs nonopioid analgesics). However, the approach has led to a more restrictive cohort that inadvertently limited the generalizability of our findings.

\section{Conclusions}

Our findings indicated that asthma exacerbation is uncommon following the dispensing of an opioid or nonopioid analgesic medication in children with current asthma. There was no significant difference in the odds of asthma exacerbation following the dispensing of opioid vs nonopioid analgesics.

\section{DISCLOSURES}

This study was supported and funded by the Agency for Healthcare Research and Quality (AHRQ), Project Number: 1R03HS026790-01A1. The study content was solely the responsibility of the authors, and AHRQ had no role in the design and conduct of the study. The authors have nothing to disclose.

\section{REFERENCES}

1. Centers for Disease Control and Prevention. National Health Intervirew Survey (NHIS) data. 2021. Accessed March 10, 2021. https://www.cdc.gov/asthma/ nhis/default.htm

2. Centers for Disease Control and Prevention. Most recent asthma data, data statistics and surveillance, asthma. 2021. Accessed April 05, 2021. https://www. cdc.gov/asthma/most recent national asthma_data.htm

3. Sala KA, Carroll CL, Tang YS, Aglio T, Dressler AM, Schramm CM. Factors associated with the development of severe asthma exacerbations in children. J Asthma. 2011;48(6):558-64. doi:10.3109/0 2770903.2011.585411

4. Werner HA. Status asthmaticus in children: a review. Chest. 2001;119(6):1913-29. doi:10.1378/chest.119.6.1913 
5. Rizeq YK, Many BT, Vacek JC, et al. Trends in perioperative opioid and non-opioid utilization during ambulatory surgery in children. Surgery. 2019;166(2):172-76. doi:10.1016/j. surg.2019.04.005

6. Harbaugh CM, Lee JS, Hu HM, et al. Persistent opioid use among pediatric patients after surgery. Pediatrics. 2018;141(1):e20172439. doi:10.1542/ peds.2017-2439

7. Jakobsson J. Pain management in ambulatory surgery-a review. Pharmaceuticals (Basel). 2014;7(8):850-65. doi:10.3390/ ph7080850

8. Hysingla ER. Prescribing information. Purdue Pharma LP; March 2016. Accessed February 22, 2020. http://app.purduepharma.com/xmlpublishing/pi.aspx?id=h

9. Capital and Codeine Suspension. Prescribing information. Valeant Pharmaceuticals; April 2016. Accesed June 14, 2020. https://www.bauschhealth.com/ Portals/25/Pdf/PI/CapitalCodeine-PI.pdf

10. Ultram. Prescribing information. Janssen Pharmaceuticals; August 2019. Accessed June 18, 2020. http://www. janssenlabels.com/package-insert/ product-monograph/prescribing-information/ULTRAM-pi.pdf

11. Tylenol with Codeine CIII. Prescribing information. Janssen Pharmaceuticals; August 2019. Accessed June 18, 2020. https://online.lexi.com/lco/medguides/ 648425.pdf

12. Boom M, Niesters M, Sarton E, Aarts L, Smith TW, Dahan A.

Non-analgesic effects of opioids: opioidinduced respiratory depression. Curr Pharm Des. 2012;18(37):5994-6004. doi:10.2174/138161212803582469

13. Jungquist CR, Karan S, Perlis ML. Risk factors for opioid-induced excessive respiratory depression. Pain Manag Nurs. 2011;12(3):180-87. doi:10.1016/j. pmn.2010.02.001

14. Radke JB, Owen KP, Sutter ME, Ford JB, Albertson TE. The effects of opioids on the lung. Clin Rev Allergy Immunol. 2014;46(1):54-64. doi:10.1007/ s12016-013-8373-Z
15. Dahan A, Aarts L, Smith TW. Incidence, reversal, and prevention of opioid-induced respiratory depression. Anesthesiology. 2010;112(1):226-38. doi:10.1097/ALN.0b013e 3181c38c25

16. Martin WR. Opioid antagonists. Pharmacol Rev. 1967;19(4):463-521.

17. Song JW, Chung KC. Observational studies: cohort and case-control studies. Plast Reconstr Surg. 2010;126(6):2234-42. doi:10.1097/PRS.0b013e3181f44abc

18. Everitt B, Palmer C. Encyclopaedic Companion to Medical Statistics. 2nd ed. Wiley; 2011.

19. US Food and Drug Administration. FDA Drug Safety Podcast: FDA restricts use of prescription codeine pain and cough medicines and tramadol pain medicines in children; recommends against use in breastfeeding women. April 26, 2017. Accessed December 2020. https://www. fda.gov/drugs/fda-drug-safety-podcasts / fda-drug-safety-podcast-fda-restrictsuse-prescription-codeine-pain-andcough-medicines-and-tramadol

20. US Food and Drug Administration. FDA Drug Safety Communication. FDA requires labeling changes for prescription opioid cough and cold medicines to limit their use to adults 18 years and older. April 20, 2017. Updated January 1, 2018. Accessed December 2020. https://www.fda.gov/ drugs/drug-safety-and-availability/ fda-drug-safety-communication-fdarequires-labeling-changes-prescriptionopioid-cough-and-cold

21. Akinbami LJ, Moorman JE, Liu X. Asthma prevalence, health care use, and mortality: United States, 2005-2009. Natl Health Stat Report. 2011;(32):1-14.

22. Arellano FM, Arana A, Wentworth CE, Vidaurre CF, Chipps BE. Prescription patterns for asthma medications in children and adolescents with health care insurance in the United States. Pediatr Allergy Immunol. 2011;22(5):469-76. doi:10.1111/j.1399-3038.2010.01121.x
23. Chastek B, Korrer S, Nagar SP, et al. Economic burden of illness among patients with severe asthma in a managed care setting. J Manag Care Spec Pharm. 2016;22(7):848-61. doi:10.18553/ jmcp.2016.22.7.848

24. Dombkowski KJ, Wasilevich EA, Lyon-Callo SK. Pediatric asthma surveillance using Medicaid claims. Public Health Rep. 2005;120(5):515-24. doi:10.1177/003335490512000506

25. Farber HJ, Silveira EA, Vicere DR, Kothari VD, Giardino AP. Oral corticosteroid prescribing for children with asthma in a Medicaid managed care program. Pediatrics. 2017;139(5):e20164146. doi:10.1542/peds.2016-4146

26. Fuhlbrigge A, Peden D, Apter AJ, et al. Asthma outcomes: exacerbations. J Allergy Clin Immunol. 2012;129(3 Suppl):S34-48. doi:10.1016/j.jaci.2011.12.983

27. Sims EJ, Price D, Haughney J, Ryan D, Thomas M. Current control and future risk in asthma management. Allergy Asthma Immunol Res. 2011;3(4):217-25. doi:10.4168/aair.2011.3.4.217

28. Suruki RY, Boudiaf N, Ortega HG. Retrospective cohort analysis of healthcare claims in the United States characterising asthma exacerbations in paediatric patients. World Allergy Organ J. 2016;9(1):18. doi:10.1186/s40413-016-0109-0

29. Suruki RY, Daugherty JB, Boudiaf N, Albers FC. The frequency of asthma exacerbations and healthcare utilization in patients with asthma from the UK and USA. BMC Pulm Med. 2017;17(1):74. doi:10.1186/s12890-017-0409-3

30. Reddel HK, Taylor DR, Bateman ED, et al. An official American Thoracic Society/European Respiratory Society statement: asthma control and exacerbations: standardizing endpoints for clinical asthma trials and clinical practice. Am J Respir Crit Care Med. 2009;180(1):59-99. doi:10.1164/rccm.200801-060ST

31. Andersen RM. Revisiting the behavioral model and access to medical care: does it matter? J Health Soc Behav. 1995;36(1):1-10. 
32. Andersen RM. National health surveys and the behavioral model of health services use. Med Care. 2008;46(7):647-53. doi:10.1097/MLR.0b013e31817a835d

33. Nwaru BI, Ekstrom M, Hasvold P, Wiklund F, Telg G, Janson C. Overuse of short-acting beta2-agonists in asthma is associated with increased risk of exacerbation and mortality: a nationwide cohort study of the global SABINA programme. Eur Respir J. 2020;55(4):1901872. doi:10.1183/13993003.01872-2019

34. Silver HS, Blanchette CM, Kamble $\mathrm{S}$, et al. Relationship between shortacting beta2-adrenergic agonist use and healthcare costs. Am J Manag Care. 2011;17(1):19-27.

35. Brookhart MA, Wyss R, Layton JB, Sturmer T. Propensity score methods for confounding control in nonexperimental research. Circ Cardiovasc Qual Outcomes. 2013;6(5):604-11. doi:10.1161/ CIRCOUTCOMES.113.000359
36. Schulte PJ, Mascha EJ. Propensity score methods: theory and practice for anesthesia research. Anesth Analg. 2018;127(4):1074-84. doi:10.1213/ ANE.0000000000002920

37. SAS Institute Inc. SAS/STAT® 142 User's Guide. 2016. Accessed October 10, 2019. https://support.sas.com/documentation/onlinedoc/stat/142/psmatch.pdf

38. SAS Institute Inc. SAS Enterprise Guide 8.1. Version 8.1. 2019. Accessed October 10, 2019. https://support.sas. com/en/software/enterprise-guidesupport.html

39. Niesters M, Overdyk F, Smith T, Aarts L, Dahan A. Opioid-induced respiratory depression in paediatrics: a review of case reports. Br J Anaesth. 2013;110(2):175-82. doi:10.1093/bja/aes447

40. Caponnetto P, Auditore R, Russo C, et al. "Dangerous Relationships": asthma and substance abuse. J Addict Dis. 2013;32(2):158-67. doi:10.1080/10550887.2 $\underline{013.795469}$
41. Doshi V, Shenoy S, Ganesh A, Rishi MA, Molnar J, Henkle J. Profile of acute asthma exacerbation in drug users. Am J Ther. 2017;24(1):e39-43. doi:10.1097/ MJT.0000000000000118

42. Underner M, Perriot J, Peiffer G, Jaafari N. Asthma and heroin use. La Presse Médicale. 2017;46(7-8):660-75. doi:10.1016/j.lpm.2017.06.002

43. Parmar MS. Exacerbation of asthma secondary to fentanyl transdermal patch. BMJ Case Rep. 2009;2009:bcr10.2008.1062. doi:10.1136/bcr.10.2008.1062

44. Oliver P, Hulin J, Mitchell C. A primary care database study of asthma among patients with and without opioid use disorders. NPJ Prim Care Respir Med. 2020;30(1):17. doi:10.1038/ s41533-020-0174-2 